\title{
Electrochemical Methods in Nanomaterials Preparation
}

\author{
B. Kalska-Szostko \\ University of Bialytsok, Institute of Chemistry, \\ Poland
}

\section{Introduction}

Nanotechnology has become the most fashionable science since the end of the last century. Since then, a lot of effort has been made to achieve numbers of multifunctional materials with simple synthetic procedure. At the same time, investigations of easy processing for subsequent applications have become more and more popular as well. Chemical and electrochemical preparation methods are one of the possible and powerful options for the fabrication of a new class of nanomaterials. Many popular methods used for nanostructures fabrication need to involve very expensive devices like: UHV chambers equipped with MBE or sputtering, etc. It is useful to develop methods which are less expensive and lead to similar quality final products. From the application point of view, methods which allow to perform mass production in a relatively easy way were sought. Such a method is electrochemistry, which allows us to deposit a large variety of materials in many different forms from various solutions. Chemical methods also provide an opportunity to obtain nanomaterials in big quantities. Recently, hybrid nanomaterials and nanocomposites have been studied extensively because of new opportunities of the fabrication of a novel class of materials which use nanostructures as building blocks. Such subsequent hierarchical ordering of constituent nanoelements often enhance their needed magnetic, electrical, optical, structural and mechanical properties and extinct unneeded one [1]. In many cases, the tubular or elongated structures have a significant advantage over the round ones due to a possible selective interaction with the environment with or without linkage chemistry.

The nanostructures presented in this chapter were obtained by electrochemical methods [2] in matrixes possessing proper pores. Fabricated nanowires and nanotubes were deposited in anodic porous alumina template (AAO) with a pore diameter ranging from 40 to $230 \mathrm{~nm}$ [3].

Electrochemical deposition is a very attractive method because the process is simple and effective. There is a huge variety of possibly reduced ions, and it has no limitation as far as sample shape and size are concerned. Deposition of the layer can be done both in constant, also called direct (DC), and accelerating current (AC) modes depending on the needs, possibilities or applications and wires characteristics. In the first case, constant current is applied to electrodes whereas in the second one the potential of working electrode is controlled. Electrochemical deposition of nanowires is a technique which combines either bottom-up or top-down approaches. This is due to the fact that the wires have grown atom 
by atom manner and it can be obtained in the matrixes which were subjected to anodization process during which the nanopores are obtained in bulk material.

Before the templates can be used for the deposition of, e.g., nanowires or nanotubes, it should obey few requirements:

- $\quad$ it should be chemically inactive in a particular process;

- deposited material should wet the pores wall;

- deposition process should not be chaotic and start from the bottom or from the wall of the pore and go upwards or to the centre, respectively;

\section{Preparation of AAO matrix}

The most effective method to fabricate nanowires in large quantities is their deposition in porous matrixes. One of possible templates is nanoporous anodic alumina oxide (AAO). The AAO membranes can be obtained with various pores size and distance between them. The process condition such as: temperature of anodization process, composition of the used solution and current parameters, determine matrix parameters (pore diameter and distance between each other). The quality of alumina templates meaning the ordering of nanopores can be improved by a number of repeated anodization processes. The more repetitions of anodization processes are used, the better self organization of the pores at the surface is obtained. An example of such dependence is depicted in Fig. 1, where pore diameter dependence from current potential or temperature of the processes is shown.
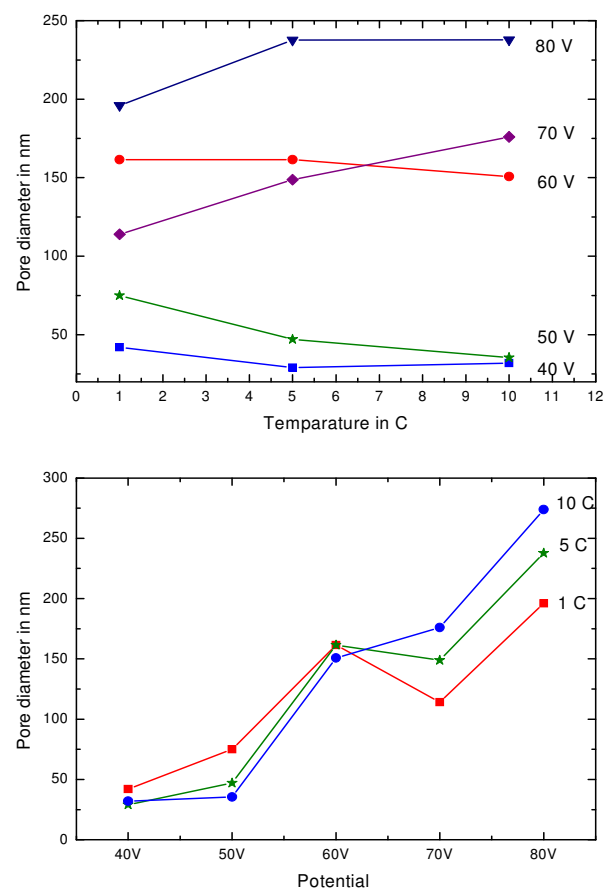

Fig. 1. Pores diameter dependence on temperature and potential. 
Such parameters as pore diameter and average distance between them as well as length strongly depend on electrolyte composition besides temperature and current conditions. Most popular solutions used as electrolytes are phosphoric acid, oxalic acid and sulfuric aide. According to the equation presented below, there is dependence between anodization potential $U$ and distance between pores $D_{c}(1)$ [4]:

$$
D_{c}=d+2 \alpha U
$$

Where: $d$ - pores diameter, a - proportional coefficient (its value vary between 2,5 $2,8 \mathrm{~nm} / \mathrm{V})$

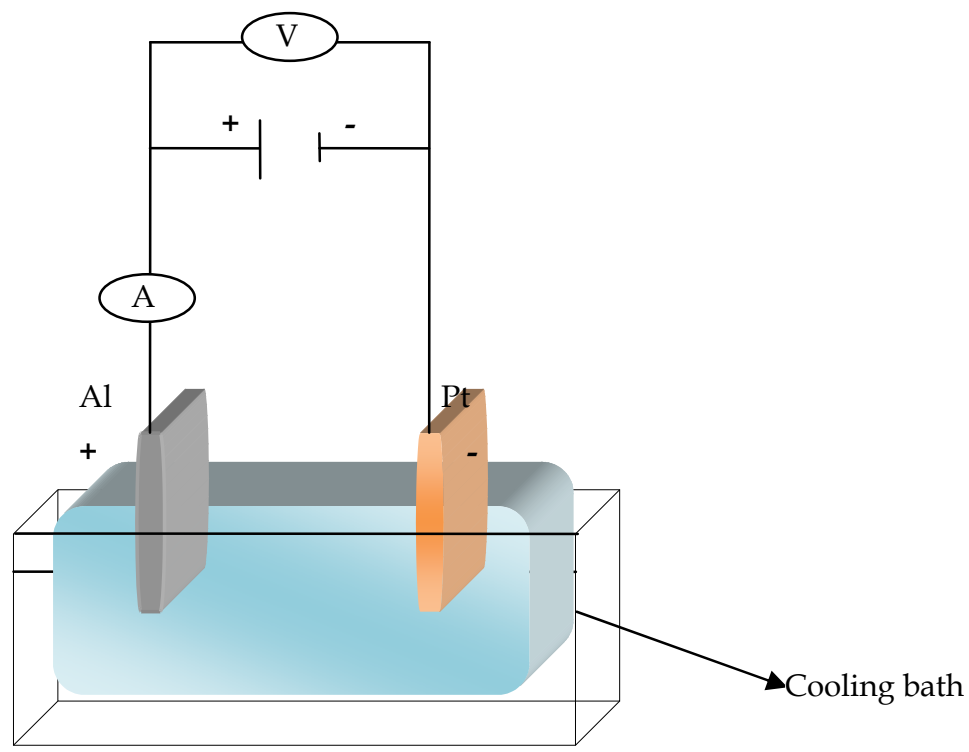

Fig. 2. Simple sketch of electrochemical double electrode cell.

In Fig. 2, a simple sketch of electrochemical double electrode cell is depicted. Here the positive electrode anode is aluminum sheet and negative electrode - Pt plate. The whole cell with the working solution is placed in a cooling bath.

To obtain good quality anodic alumina templates, few steps process should be performed.

Before the proper anodization process is done, initial degreasing, heating and electropolishing are performed. Dissolution of organic grease, oils and dust originating from technological processes from the plate surface is necessary to perform proper anodization process. It can be done, for example, by bathing $\mathrm{Al}$ plates for $10 \mathrm{~min}$ at room temperature in acetone.

Aluminum is a metal which covers immediately in contact with atmospheric oxygen or water by passive oxide layer according to the reactions (2-3) [5]:

$$
2 \mathrm{Al}+\frac{3}{2} \mathrm{O}_{2} \rightarrow \alpha \mathrm{Al}_{2} \mathrm{O}_{3}
$$




$$
2 \mathrm{Al}+3 \mathrm{H}_{2} \mathrm{O} \rightarrow \alpha \mathrm{Al}_{2} \mathrm{O}_{3}+3 \mathrm{H}_{2}
$$

High negative value of Gibbs free energy $\left(\Delta \mathrm{G}^{\circ}=-1582 \mathrm{~kJ} / \mathrm{mol}\right.$ and $\Delta \mathrm{G}^{\circ}=-871 \mathrm{~kJ} / \mathrm{mol}$, respectively) proves high efficiency of spontaneous oxidation process [6].

This layer can be removed by dissolution in mixture of $\mathrm{HNO}_{3}: \mathrm{HCl}: \mathrm{H}_{2} \mathrm{O}$ in molar ratio 10:20:70 [7], at room temperature for minimum 5 min time according to the following reaction (4):

$$
\mathrm{Al}_{2} \mathrm{O}_{3}+6 \mathrm{HNO}_{3} \rightarrow 2 \mathrm{Al}\left(\mathrm{NO}_{3}\right)_{3}+3 \mathrm{H}_{2} \mathrm{O}
$$

Such process is called surface activation and can be also performed in alkaline solution at elevated temperature around $50-60^{\circ} \mathrm{C}$ according to the equation (5):

$$
\mathrm{Al}_{2} \mathrm{O}_{3}+2 \mathrm{NaOH}+3 \mathrm{H}_{2} \mathrm{O} \rightarrow 2 \mathrm{Na}\left[\mathrm{Al}(\mathrm{OH})_{4}\right]
$$

All these initial steps are required to obtain good regularity pores in matrix and/or better attachment of deposited material.

Electropolishing process takes place when electrode surface is covered by a sticky layer which has resistance much higher than electrolyte. In such instance, part of the Al surface which is higher is covered by a much thinner layer and the current density will be higher in this places. For parts where valley are present at the surface, the high resistant layer will be thicker and much less current will penetrate through (Fig. 3). In such a way, the hills will be dissolved and in effect the surface will become less rough.

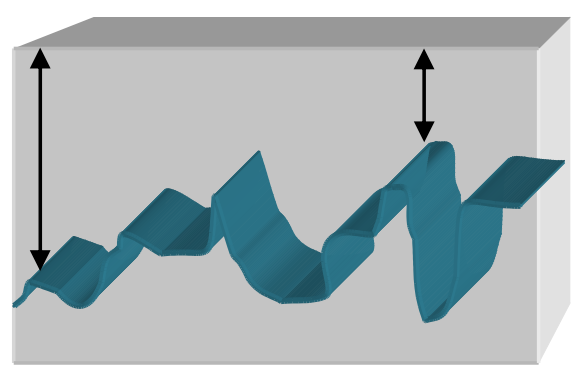

(a)

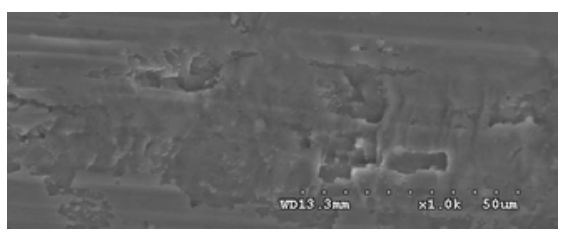

(c)

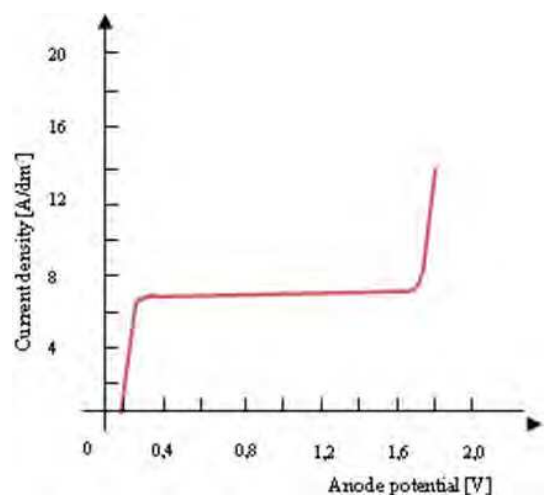

(b)

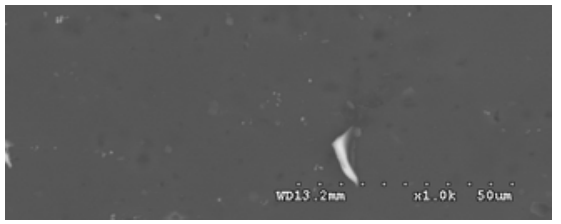

(d)

Fig. 3. a) principle of polishing process; b) polarization principles c) SEM image of nonpolished and d) polished $\mathrm{Al}$ surface after $10 \mathrm{~min}$ process at room temperature in mixture of $\mathrm{HClO}_{4}: \mathrm{C}_{2} \mathrm{H}_{5} \mathrm{OH}$ in molar ratio $75: 25[7 \mathrm{~b}]$. 
As the next step, heating at $200^{\circ}-500{ }^{\circ} \mathrm{C}$ for minimum 3 hours in inert atmosphere is needed to diminish surface roughness, stress, microcracks or other type defects caused by the production process of aluminum sheet. At elevated temperature the metal recovers and recrystallization process takes place [7a].

To find out what current parameters should be used for the polishing process, one should run polarization curves and mark out plateau where current density will change very little and the polishing process should be stable.

As it can be seen above, the resulting surface after the polishing process is characterized by much less surface defects and roughness, is more shiny, shows better reflection and better tribological properties. Removing technological origin microstructures guarantees better self-organization of pores at the $\mathrm{Al}$ surface.

Anodization process is anodic oxidation of the electrode material. In case of anodic alumina oxide, the initially continuous surface of $\mathrm{Al}$ plate becomes structured and has a unique ordered porous structure. The order of pores and their quality can be tuned by the process condition and current parameters. The effects of the conditions changes on the matrix structural parameters are depicted in Fig. 4.
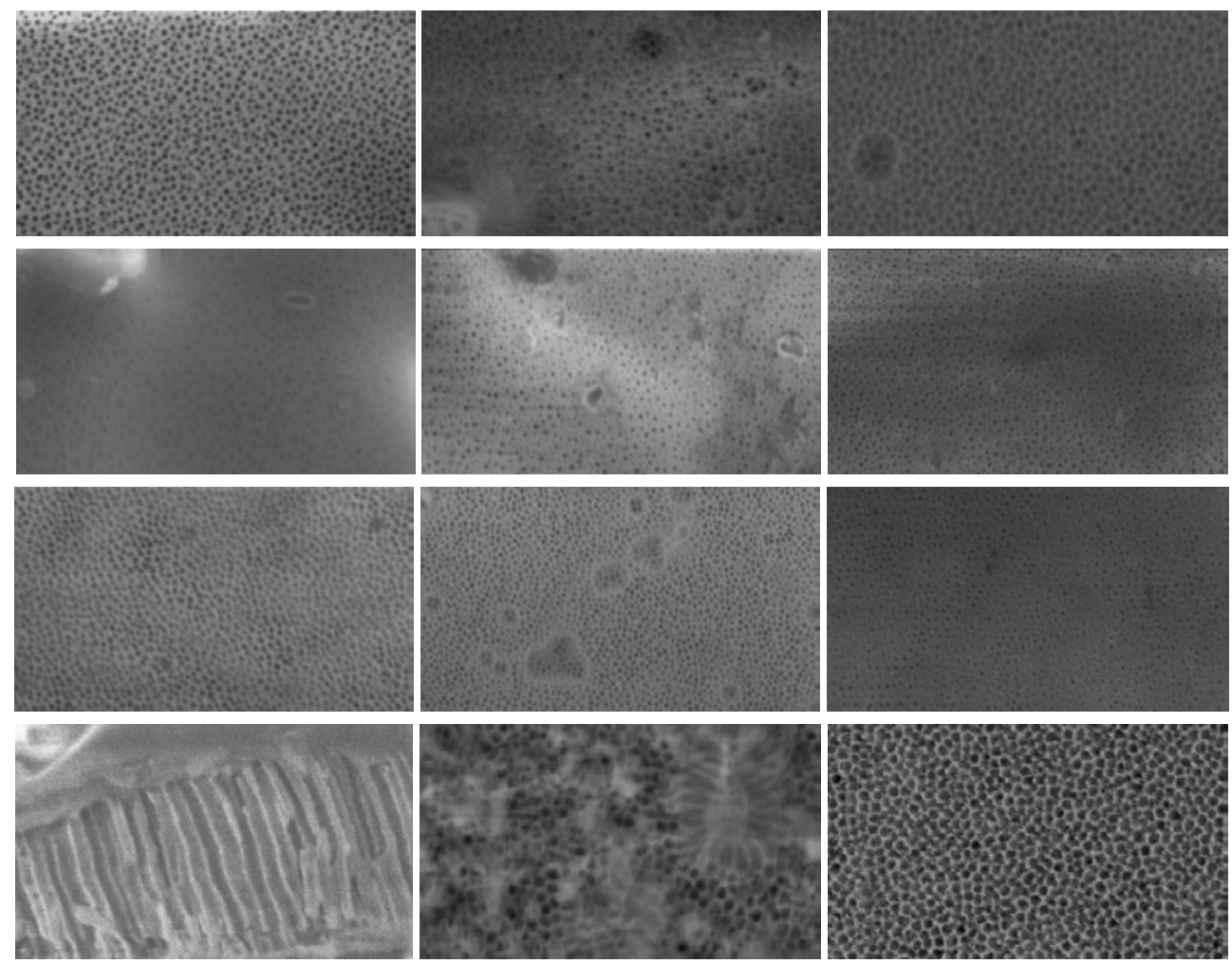

Fig. 4. Examples of porous alumina oxide surface topography and pores cross section. 
The images of the pores presented above prove that in large range pores diameter and distance between them can be tuned by process and current parameters. The obtained example cross section image of that presents that the template pores are rather even and well defined.

During anodization process two parallel reactions are taking place:

- $\quad$ the first one at the interface metal/oxide, where $\mathrm{Al}^{3+}$ ions migrate to oxide layer (6) [8]:

$$
A l \rightarrow A l^{3+}+3 e^{-}
$$

- the second one at the interface oxide layer/electrolyte, from where oxide penetrates the metal layer (7):

$$
\frac{3}{2} \mathrm{H}_{2} \mathrm{O} \rightarrow 3 \mathrm{H}^{+}+\frac{3}{2} \mathrm{O}^{2-}
$$

Formed ions $\mathrm{Al}^{3+}$ and $\mathrm{O}^{2-}$ migrate to the interface metal/oxide and form $\mathrm{Al}_{2} \mathrm{O}_{3}$.

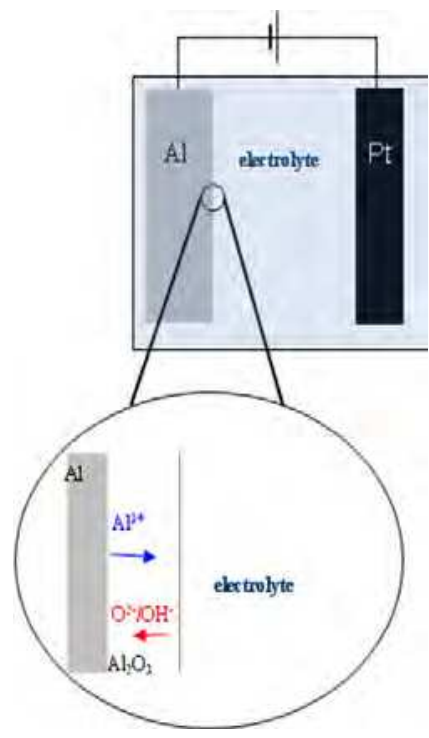

(a)

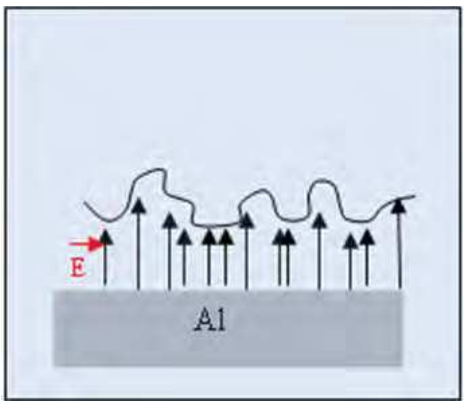

(b)

Fig. 5. Schematic sketch of: processes proceed at the electrode surface (a), alumina oxide quality (b).

Parallel to the reaction mentioned above, dissolution of the oxide takes place according to the scheme (8):

$$
\frac{1}{2} \mathrm{Al}_{2} \mathrm{O}_{3}+3 \mathrm{H}^{+} \rightarrow \mathrm{Al}^{3+}+\frac{3}{2} \mathrm{H}_{2} \mathrm{O}
$$

This shows that both processes creation and dissolution of the oxide run at the same time, and to obtain needed porous oxide layer, the first one should dominate over the second one, respectively. The best ratio between the both processes is 7:3 [9]. 
The temperature of anodization electrolyte should be lower than room temperature to avoid too fast alumina dissolution process. Low temperature also prevents local overheating of the Al plate, which can cause cracking and pill of the alumina layer. Such unwanted effect is presented in Fig. 6 a.

Anodization potential influences not only pores size but also their ordering. However, applying to a large value of potential can effect in surface degradation, which is shown in Fig. 6 b.

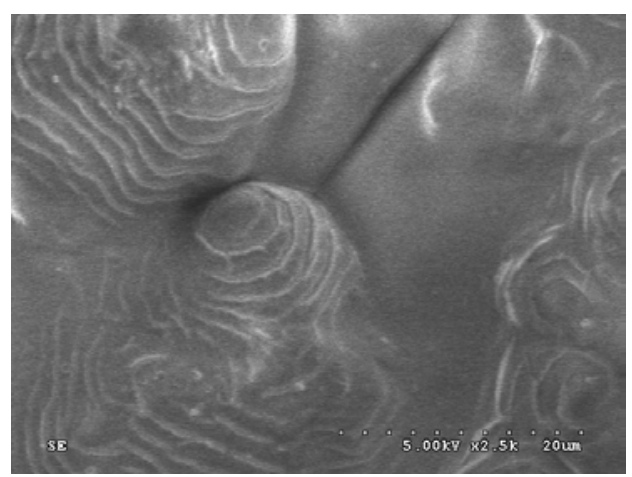

(a)

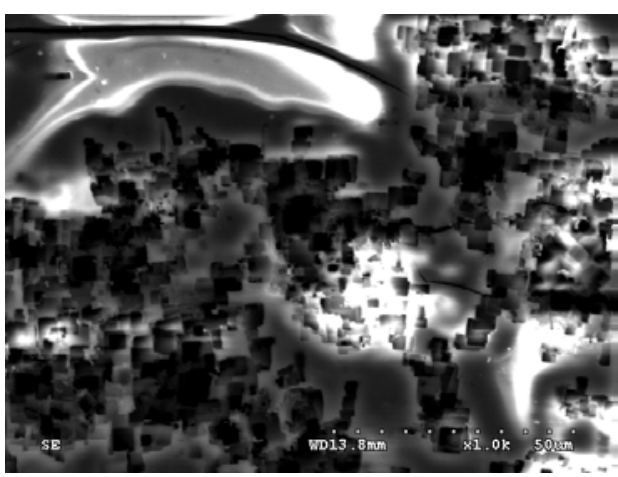

(b)

Fig. 6. a) effect of too high temperature of solution; b) effect of too high anodization potential.

At first stage, $\mathrm{Al}$ surface is covered by flat barrier oxide layer which is conducting very little $\left(10^{10} \sim 10^{12} \Omega \mathrm{cm}\right)[10]$. At the next stage, this layer becomes more and more rough and corrugated, which results in local increasing of the current density, which therefore causes the increase of temperature and dissolving of the oxide layer also locally. In such a way, the pores are created. Prolongation of anodization process influences the diameter of obtained pores, a distance between them and their ordering.

The matrix prepared in such a way is not yet ready to use because at the surface the barrier oxide layer is present. This layer contains impurity from the solution and should be dissolved in one of the following solutions: mixture of $6 \% \mathrm{H}_{3} \mathrm{PO}_{4}$ and $1,8 \% \mathrm{H}_{2} \mathrm{C}_{2} \mathrm{O}_{4}, 5 \%$ solution of $\mathrm{H}_{3} \mathrm{PO}_{4}$, mixture of $1 \mathrm{M} \mathrm{H}_{2} \mathrm{SO}_{4}$ and $2 \mathrm{M} \mathrm{H}_{3} \mathrm{PO}_{4}$, solution of $\mathrm{HgCl}_{2}$ (saturated) [11]. To illustrate the effect of this process, please look at the last row of Fig. 4.

Finally, a perfect ordered porous alumina layer is obtained (see Fig.7).

\section{Deposition of the materials}

Two kinds of deposition processes can be considered with controlled potential or current. Current controlling demands two electrode system with voltmeter and ampere-meter devices.

Controlling of the potential adjusted to a stable value is performed in three electrode setups, where, besides working and reference, a counter electrode is needed. This electrode should be chosen in such a way that it has a significant surface so that the current obtained 


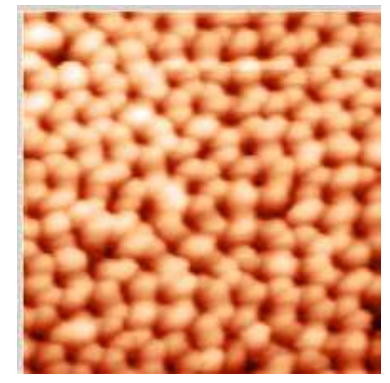

(a)

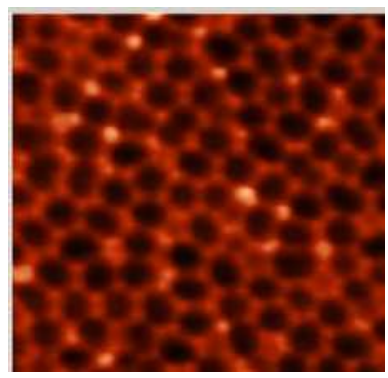

(b)

Fig. 7. AFM images of final matrixes: a) oxalic acid, b) phosphoric acid.

in the electrolysis process is not changing its potential. This electrode is applied to the working electrode's constant current, which stabilizes constant potential in the reference electrode. A potential value of the electrode is controlled by potentiostat.

Accelerating current mode demands a two electrode device, where working and reference electrodes can be made from the same material.

Constant current deposition can be carried out without adjusting other current parameters before the deposition process. In case of deposition with the controlled potential, its value should be calculated from the equations described below to assure large enough process efficiency. It is also possible to run voltoamperometric or chronoamperometric curves and on its ground a characteristic value of the deposition process is established. Such specific potential has to be calculated for every type of electrolyte and electrodes.

Electrodeposition is a method by which ions from the solution are deposited at the surface of the cathode (working electrode). This process can run parallel to electrolysis, and deposited material can form a continuous layer, wires or tubes when prestructured matrixes are used. The amount of the deposited material, thickness of the layer or wires length depend on the deposition time matrix structure.

Electrolysis is a number of processes taking place in electrolyte and at electrode interfaces while electrical current is applied from external sources. In electrolysis the change from electrical energy to chemical potential takes place. The most important reactions proceed at the interfaces electrode metal/solution. When the electrode is dissolved and in oxide form is present in the solution, this electrode we call anode. The opposite electrode - cathode, is one where ions are reduced and metallic surface is formed. During the electrolysis process, large gradients of ions concentrations are observed. The reactions taking place at the electrodes are described in the following form [12]:

$$
\begin{aligned}
& C(-): O x_{A}+z_{A} e \rightarrow \operatorname{Re} d_{A} \\
& A(+): \operatorname{Re} d_{B} \rightarrow O x_{B}+z_{B} e
\end{aligned}
$$

In a two electrode system, both electrodes are connected to a proper potential source. Current starts to increase when the value of decomposition potential $U_{r}$ is exceeded (Fig. 8). After that, the value of potential electrolysis can be used in a practical application. 


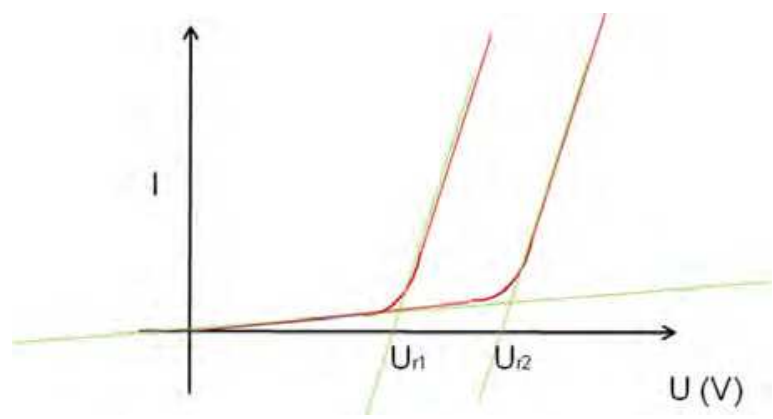

Fig. 8. Drawing of potential changes during electrodeposition process.

Decomposition potential can be described in the following way (12):

$$
U_{r}=S E M+I R
$$

Where: SEM - electromotive force of cell, $I$ - current, $R$ - resistance

Theoretically, this potential should increase by the value $\left(E_{A}-E c\right)$, where $E_{A}$ - anode potential, $E c$ - cathode potential, which is needed to obtain current $I$ and resistivity.

In reality, decomposition potential between two electrodes is higher compared to the theoretical one by the value of overpotential $\eta[12]$ :

$$
U=\left(E_{A}-E_{C}\right)+I R+\eta
$$

Overpotential is present due to deviation of electrodes potential from equilibrium value during current flow. The reasons why such phenomenon is present are the following: to slow ion diffusion from solution to electrodes, to slow velocity of redox reactions, delay in crystallization processes and electrode surface, too big difference of ions concentration in electrolyte. The value of overpotential depends on: a type of electrode, electrode surface quality, current density, and temperature of electrolyte.

Electrolysis process is a few stage process: (i) ion transportation in electrolyte from one electrode to the opposite one; (ii) chemical reaction with electrical charge transfer at the interface electrode/solution; (iii) other type of surface reactions - adsorption, desorption, crystallization.

Faraday law defines dependence between current flow through solution and amount of material reduced at the electrodes. The first law - mass of material deposited at electrodes is proportional to the amount of current flow through electrolyte, which is described by the equation [13]:

$$
m=k \cdot Q=k \cdot I \cdot t
$$

where: $m$ - mass of material reduced at electrode;

$k$ - electrochemical equivalent

$Q$ - charge

$I$ - current

$t$ - time 
The second Faraday law - mass of different substances deposited at electrodes during flow of equal charge is proportional to its electrochemical equivalent according to the equation [14]:

$$
\frac{m}{Q}=\frac{1}{F} \cdot \frac{M}{n} \text { or } F=\frac{Q}{m} \cdot \frac{M}{n}
$$

where: $\quad F$-Faraday constant $(96500 \mathrm{C})$

$M$ - molar mass

$n$ - number of electrons in the process

Before each deposition process it is preferable to run voltamperometric or chronovoltamperometric curves to optimize current parameters of the process. Voltamperometric dependence is current function of potential which changes in a way shown in Fig. 9 (a). Intensity of peak and at the same time current value can be calculated according to Randles - Sevčik equation [15]. In cyclic curve two peaks can be observed: cathodic reduction and anodic oxidation of the ions Fig. 9 (b). To obtain deposition with reasonable effect, deposition should be conducted in a range of cathodic reduction peak.

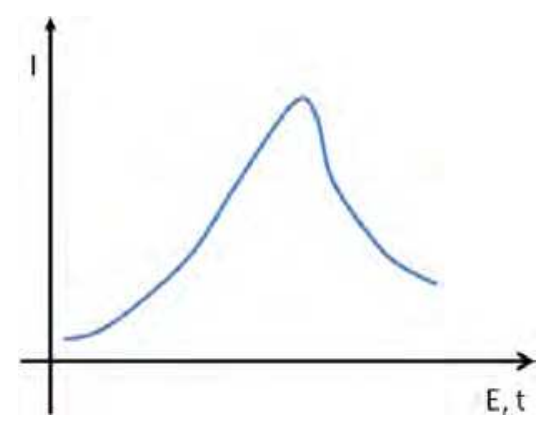

(a)

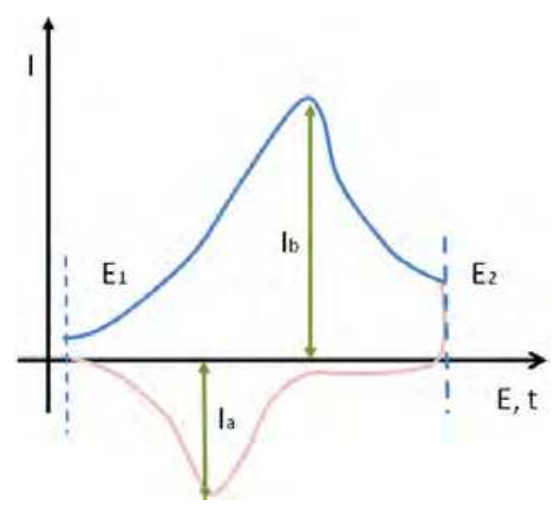

(b)

Fig. 9. (a) Typical voltamperomertic curve $\mathrm{I}=\mathrm{f}(\mathrm{E})$, (b) typical cyclic voltoamperometric curve.

In addition to these two methods, chronoamperometric dependence $I=f(t)$ should be done, where the value of current is monitored as a function of potential. Such measurement gives us additional qualitative and quantitative information about electrolyte composition, speed of electrode processes and chemical reaction taking place at the electrodes and in electrolyte. These curves inform about electrode deposition process [15]. Chronoamperometric curves should be registered at potential exceeding overpotential value. By collecting these curves for few potential values best deposition condition can be determined.

Current parameters for each particular deposition process should be estimated for each electrochemical cell and electrolyte.

Electrochemically deposited material has in most cases a crystalline structure but the quality of the obtained layers can be different due to the various speed of crystal growth and crystal seeds creation. Modification of few parameters such as: current density, type and 
concentration of electrolyte, $\mathrm{pH}$ of electrolyte, temperature, presence of surfactants, matrix properties, etc., has significant influence on the quality of deposited material. For each material a range of parameters giving best quality surface can be assigned.

Current density is a ratio between total current value and electrode surface. This is probably the most important parameter defining quality of deposited material. For low current density, its value coarse surface can be obtained because the speed of nucleation centers creation is much lower compared to crystal growth of the existing seeds. For high current density, quite often a decrease of ions concentration close to the deposited surface is observed, or hydrogen evolution takes place and the obtained layers become noncontinuous, spongy and porous. To avoid non-equal current density in deposition process, a parallel arrangement of electrodes in the centre of vessels should be assured. In case of nanowires, deposition proper current density should be well matched to protect hydroxide and cracks or discontinuous inclusion of the wire creation. This avoids too fast degradation of the wires during fabrication processes and assures good electrical conductivity [12].

$\mathrm{pH}$ variation also influences surface morphology heavily. Low $\mathrm{pH}$ causes hydrogen evolution, which penetrates the layer, and deposited material becomes harder, and it introduces a lot of stress to the layer. $\mathrm{pH}$ also influences magnetic properties of deposited material. Because of that, electrodeposition process should be conducted at a stable value of $\mathrm{pH}$, any variation can be compensated by the addition of alkaline or acidic media [12].

Electrolyte concentration - increase of electrolyte concentration, effects in continuously grown and well attached layers. Growth speed in-plane dominates growth out-of-plane, which avoids high roughness [12]. Higher ion concentration allows to work with higher current density without the risk of hydrogen evolution. A very similar effect is observed in case of solution stirring because it eliminates the concentration of gradients in the solution.

Temperature - its increase, influences two opposite phenomena. First of all, it helps in diffusion process, which prevents rough and spongy layer growth even for high current density. On the other hand, it increases the speed of crystal growth and causes the presence of bigger crystals and hydrogen evolution. At lower temperatures, the first scenario dominates and better quality layers are obtained compared to higher temperatures. Moderate heating of electrolyte influences positively on the quality of deposited layers but too large temperature elevation gives rather bad quality surfaces [12].

The presence of surfactants in electrolyte decreases surface tension at the electrode surface and influences the release of hydrogen from the electrode surface, which is produced in hydrogen evolution process [12]. The addition of surface active substances and their adsorption at crystal surfaces stops the growth of existing agglomerates and affects nucleation of new ones. Such modification of the process helps to fabricate layers build up from small crystalline material. Very alike phenomenon is observed in case of complex ions.

Extremely important parameter which governs good quality of obtained films is used matrix, which often influences and modifies a crystal structure at least in the first layers of deposited material.

In aqueous solution of metal $M^{0}$ salts $M^{z+}$ ions are present. Placing two electrodes connected with current source into it originates the following process [13]: 


$$
M_{a q}^{z+}+z e^{-}=M^{0}
$$

The mechanism of layer deposition is quite complex and is illustrated in Fig. 10. Metal ions are covered by hydration shell, which helps in easier diffusion, convection and migration processes. These phenomena cause transport of hydrated ions in cathode direction. Close to cathode party dehydration process takes place and released ion can be placed in a crystal structure of a growing layer.

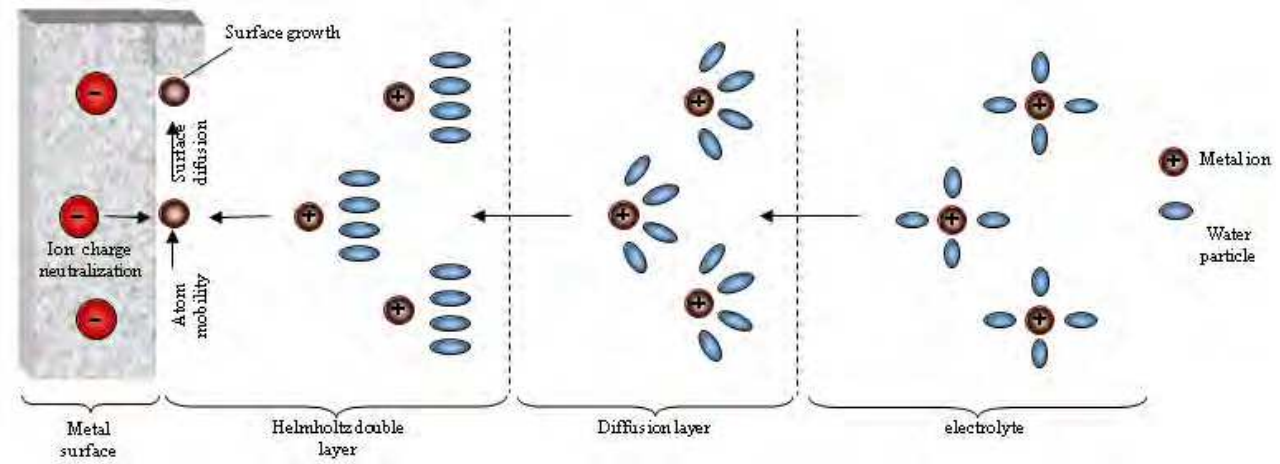

Fig. 10. Schematic drawing of the process taking place close to electrode.

In case of metal ions, deposition at electrode surface (other metal) incorporation of its into layer is not an immediate process after landing at the surface because of energetic differentiation between the sites (Fig.11). Normally, atoms migrate at the electrode surface until free defects sites with lowest energy meet.

Elecrodeposition process can be divided into two main steps: (i) seeds nucleation (when $M_{a q}^{z+}$ ion approaches the surface, loose solvation shell and its charge is reduced by charge transfer. In such a way, neutral ad-atom $M^{0}$ is formed (Fig.11). Ad-atom can migrate at the surface as long as preferred site will be reached. Most energetically favorite site is hole, next node, dislocation and least flat surface.

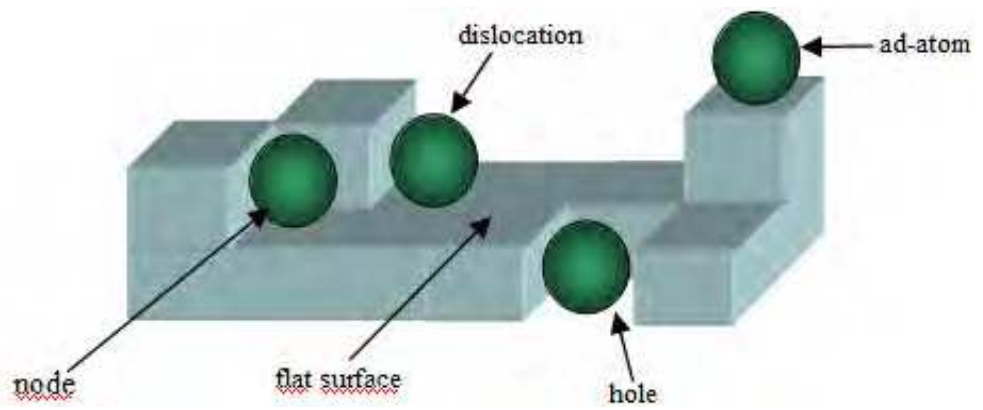

Fig. 11. Drawing of the atoms location in deposition process

These principles define electrodeposition of the material in prestructured or porous matrixes (e.g. anodic alumina oxide), where at first atoms are deposited at the bottom of the pores. 
Next, the collection of ad-atoms in agglomerates nucleates crystallization seeds of a new phase, which grows upwards. Such a scenario is very profitable because the whole pore can be used as a template for wire growth and no stuffing of the pore takes place.

Using the above phenomena, $\mathrm{Cu}, \mathrm{Ni}, \mathrm{Co}$ and $\mathrm{Fe}$ were deposited to the porous AAO matrix characterized by a different pores diameter [7]. As it was already mentioned, the deposition conditions influence strongly the quality and length of the obtained nanowires. Such structures as nanowires and nanotubes can be obtained via constant current deposition (DC) method when well distributed nanowires standing perpendicularly to the surface plane are relatively easily obtained. The acceleration current method (AC) in most cases (for long enough time of deposition) ends up with long wires which are randomly oriented at the surface due to strong magnetic interaction between them.

AC platting is often performed in a two electrode cell where working electrode is AAO plate and reference electrode $\mathrm{Pt}$ plate or wire. The example of the electrolyte composition used in the process was: $120 \mathrm{~g} / 1 \mathrm{NiSO}_{4}+40 \mathrm{~g} / \mathrm{l} \mathrm{H}_{3} \mathrm{BO}_{3}$, electrolyte: $50 \mathrm{~g} / 1 \mathrm{CoSO} 47 \mathrm{H} 2 \mathrm{O}+25 \mathrm{~g} / 1$ $\mathrm{H} 3 \mathrm{BO} 3+20 \mathrm{~g} / 1$ glycerin, $0.9 \mathrm{~mol} / 1 \mathrm{FeSO}_{4} 7 \mathrm{H}_{2} \mathrm{O}, 0.15 \mathrm{~mol} / 1 \mathrm{FeCl}_{2} 4 \mathrm{H}_{2} \mathrm{O}$ and $0.43 \mathrm{~mol} / \mathrm{l}$ $\mathrm{NH}_{4} \mathrm{Cl}$ for $\mathrm{Ni}, \mathrm{Co}, \mathrm{Fe} \mathrm{AC}$ deposition at current condition $20 \mathrm{~V}, 16 \mathrm{~V}$ and $10 \mathrm{~V}$, respectively. DC deposition required a three electrode cell and besides, two already mentioned counter electrodes as Ag wire is present [2].

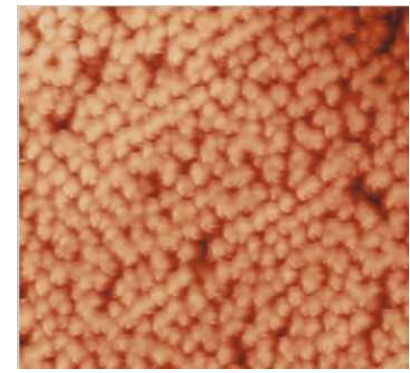

(a)

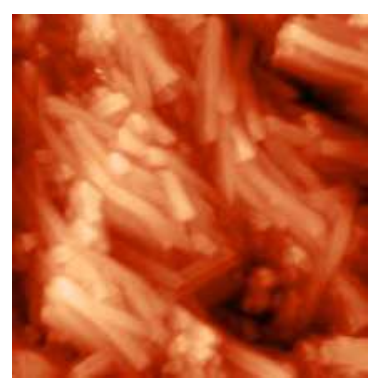

(b)

Fig. 12. Different quality of obtained wires by (a) DC and (b) AC modes

A choice of deposition mode depends on the needs and effectiveness of deposition processes. In DC mode, whole time while current is on deposition process takes place. AC plating combines deposition and dissolution processes which are running after each other. Firstly, the material is deposited and in the opposite current phase this layer is dissolved. Effective platting is only in this case when deposition dominates dissolution process.

The principles mentioned above should be modified and few additional phenomena must be considered. In general, kinetic parameters of deposition process are quite complex and depend on many parameters, which can be seen in the following equations (15-20). There are still many unknown points in deposition process which demand big effort of scientists and consume much time to be resolved. In many cases the proper and most accurate values describing the observed processes are obtained by different models. In case of porous membranes, one possible model is developed by Osterle called Space-Charge model [16]. There are modifications of this and some points are improved. In general, there are few 
equations which can be considered for the explanation of the problem and few equations must be fulfilled to understand the deposition phenomena [17]. The Nernst-Planck equation - which describes molar flux density $(J)$ present in the tube:

$$
J=-D \nabla C-K Z C Q \nabla \phi+C u
$$

Where: $D$ - diffusion coefficient (diffusivity), $C$ - ion concentration, $K$ - mobility $Z$ - valence of the ion, $Q-, \Phi$ - electrical potential, $u$ - fluid velocity

The Einstein-relation which combines dependence between mobility and diffusivity of ions [17]:

$$
K=\frac{D}{R T}
$$

The Navier-Stokes equation - describing the fluid flow in a cylindrical tube [17]:

$$
-\nabla p-F \sum_{i=1}^{2} Z C \nabla \phi+u \nabla^{2} u=0
$$

Where: $p$ - hydrostatic pressure,

\section{F - Faraday constant}

The Poisson-Boltzmann equation - which takes into account a relation between charge density and electrical potential in cylindrical coordinates [17]:

$$
\frac{\varepsilon_{0}}{r} \frac{\partial}{\partial r}\left(\varepsilon r \frac{\partial \varphi}{\partial r}\right)=\sum_{i=1} Z F c^{b} \exp \left[-\frac{Z F \varphi(r)}{R T}-\frac{A F}{e R T}\left(\frac{1}{\varepsilon}-\frac{1}{\varepsilon_{p}}\right)\right]
$$

Where: $e$ - electric charge, $r$ - hydrated radius, $\varepsilon$ - permittivity of free space, $A$ - hydration constant, $\varepsilon$ - dielectric constant.

Surface charge density - fraction of the total number of surface sites per unit area that are unbounded/charged [17]:

$$
\sigma_{s}=e\left(\left[A H_{2}^{2+}\right]_{S}-\left[A^{-}\right]_{S}\right)
$$

Where: $-A^{-}$- fixed charges, $s$-surface quantity, $H^{+}$- mobile ions,

Finite size ion effects for strongly hydrated electrolytes which consider the case of dissociated ions and full penetration in case of binary electrolytes [17]:

$$
\frac{n}{n^{b}}\left(\frac{N-n^{b}}{N-n}\right)=\exp \left[-\frac{z F \Psi(r)}{R T}-\frac{A F}{e R T}\left(\frac{1}{\varepsilon}-\frac{1}{\varepsilon_{b}}\right)\right]
$$

Where: $n$ - number of density of ions near the charged wall, $n^{b}$ - number of density of ions in the bulk, $\mathrm{N}$ - total number of vacant sites $(\mathrm{N}=1 / v$ here $v$ is the volume of the hydrated ion) 
The movement of the ions in cylindrical tubes which are characterized by small radius is impeded in proximity of the pore wall. This fact decreases ionic diffusivity, which can be described as $D_{i}$ :

$$
D_{i}=R_{i} D_{i}
$$

Where: $R_{i}$ - ion specific hydrodynamic retardation factor.

Pore fluid conductivity of the capillary tube $\left(c_{p}\right)$ can be calculated by dividing the fluid conductivity coefficient $\mathrm{K}$ by cross-section area $\left(\mathrm{a}^{2}\right)$ of the pore [17].

$$
C_{p}=\frac{K}{\pi a^{2}}
$$

In principle, pore conductivity and the electrical potential gradient should increase with the increase of ion concentration.

Apart from that, simplified assumptions (small Debye length, small surface charge density, constant surface charge and surface potential) can be used to describe electrokinetic phenomena to derive phenomenological coefficients. Simplified equations can also be based only on terms of forces and fluxes.

The characteristic parameters of electrical double layer such as electrical potential and profile of ion concentration are often modified by dielectric saturation effects, which, on the other hand, depend on the strength of electric field, and this derives from the interaction between fixed charges at, e.g., pore wall and the mobile ions present in electrolyte [18].

\section{Variation of deposited materials}

Even if a theoretical approach to electrodeposition can be done in many ways, quite often experimental results are difficult to understand because quite many parameters can vary at the same time and the variation of one of them in other order leads to completely opposite results. This is a huge problem for scientists and makes nanomaterials become very ardent but also extremely difficult topic to study.

Not only single element wires are interesting but even more promising are these which are fabricated from more than one element. Such elements can be distributed in wire body in few manners: i) alloy-like composition, ii) layered structures, iii) core-shell structures (see Fig. 13).
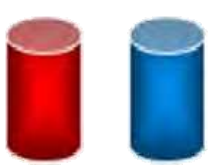

(a)
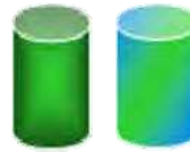

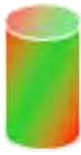

(b)

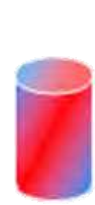

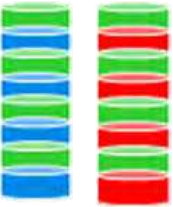

(c)

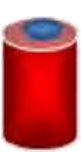

(d)

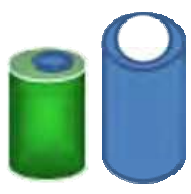

(e)

Fig. 13. Examples of possible structure modification of electrodeposited nanowires (a) single phase, (b) alloy like, (c) layered, (d) core-shell, (e) tubes. 
Depending on the application, one of these are more interesting compared to other one. The application of noble metal wires such as $\mathrm{Ag}, \mathrm{Au}, \mathrm{Pt}$ and $\mathrm{Cu}$ are interesting in bioapplication but they are almost of no use in electronic devices or sensor application. On the other hand, $\mathrm{Co}$ and $\mathrm{Ni}$ oxides are often interesting to use in electronic and sensing industry and rather no application in biotechnology can be found. For example, if one considers modification of the wire surface by a compound which is active only with metal oxides, the surface of the wire should be covered intently by such. At the same time, affinity to thiols and amine groups will show wires which posses layered structure of Ag and Fe. Such structures require modification of electrodeposition process to obey both material deposition conditions (Fig. 14).

Among elongated structures nanotubes are placed and they also have quite a large variety of possible applications. Variation of the inert structure of nanomaterials allows to estimate the best composition which obeys the best productivity of surface functionalization processes.

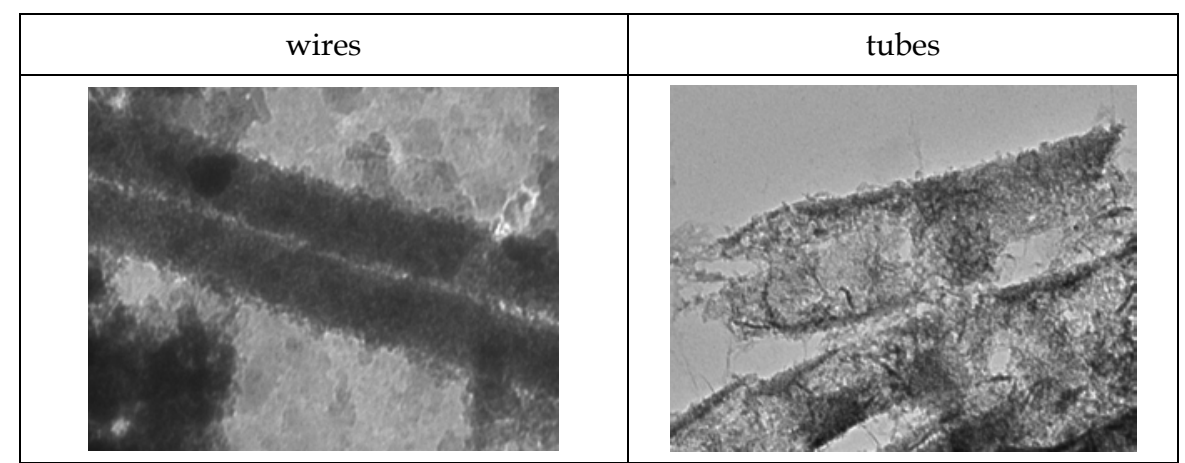

Fig. 14. TEM images of electrodeposited nanowires and nanotubes

Effectiveness of deposition process strongly depends on elements which are deposited. This problem can be faced when deposition of elements such as $\mathrm{Co}, \mathrm{Ni}$ and $\mathrm{Fe}$ in AAO matrix is compared. On the one hand, the diffusion of the ions is almost the same because we use the same type of the matrix and the radius of the ions is very alike. This suggests that the value will rather be the same for the considered elements and the same matrix. However, the difference in a growing rate of the two compared cases is observed. This uneven process can be due to dissimilar crystal growth modes in the pores. The evolution of $\mathrm{H}_{2}$ can also be not the same and it can sustain each element differently. When the surface is smoother, there are fewer nucleation centers and the atoms are worse adsorbed on the surface. On the other hand, the quality of the wires is much better compared to one which possesses a large number of the nucleation centers $[19,20]$.

Electrodeposition can also be performed in non-aqueous solution, which is valuable especially for very expensive or rare elements. Such deposition process can be done in, for example, acetone electrolyte by AC platting method, where one electrode (working) is matrix at which a layer should be deposited, and the second electrode from which the element is released (dissolved). [21] 
Wires obtained in matrixes can be released by dissolving the alumina layer by such solutions as: $0,52 \mathrm{M} \mathrm{H}_{3} \mathrm{PO}_{4}$ or $1 \mathrm{M} \mathrm{NaOH}$. Dissolution of matrix can be performed up to the stage when only a part of or until the whole template is removed from the plate surface. It depends on the particular application of fabricated nanowires [22].

\section{Composite preparation}

An interesting type of composites were these which had elongated nanostructures as nanowires or nanotubes in the structure. A special type of these are the nanostructures which are made of pure metal or metal oxide. Many of them have magnetic and at the same time conducting properties or selectively only one of them. This causes that the elements or whole composite materials can be easily manipulated by external magnetic field, which extends their application possibility. A special kind of nanocomposites are bionanocompisites, where the structure is constructed in such a way that bimolecule is already attached to the composite or can be caught by free active bonding. All non organic elements can be connected with biomolecules directly or via linkage chemistry (see Fig. 15.).

(a)

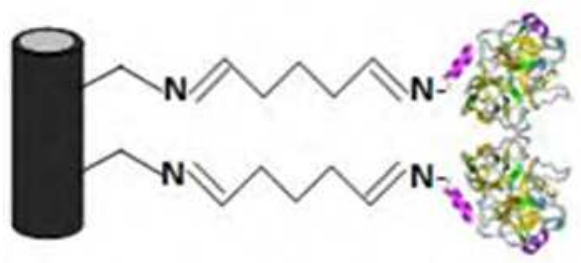

(b)

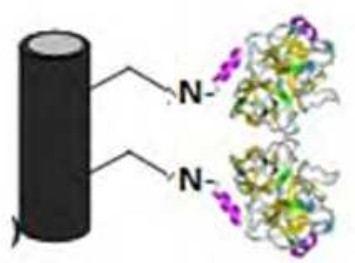

Fig. 15. Examples of biomolecule attachment to composite (a) via linkage chemistry, (b) directly.

Variation of the nanowires composition causes that properties of a particular composite can be modified in such a way that enhance needed one and weakened useless. Modification of the wires composition also influences affinity to certain linkage chemistry, which determines a particular application.

\section{Possible application of described materials}

Nanomaterials with high aspect ratio are particularly interesting due to the possibility of combining easily two kinds of totally different species. It allows to modify them by linkage chemistry, which is sensitive to various molecules. The array of nanowires can be used as chip for catching specific chemical materials. In external magnetic field manipulation of separate wires to construct long chains is possible to obtain.

Deposition of core-shell nanowires is particularly interesting when prevention from oxidation process is expected. This is particularly important when any modification of 
magnetic core is critical and application due to oxidation process is limited. Controlling of the oxide layer opens a new field in fabrication and application of electrochemically obtained nanowires.

Elongated and differentiated particles combine possible immobilization at differently active parts of particle various active particles. This opens a quite broad field of application in biology and medicine.

The possibilities in constructing new nanomaterials is huge. There is an enormous number of structures which are described in the literature. However, there is also a gigantic number of unknown structures and a lot of hard work must be performed to define and describe their properties.

\section{Acknowledgement}

I would like to thank all my students and co-workers for contribution to this work. This work was partly supported by Polish National Grant No. N N204 246435.

\section{References}

[1] P. G. Romero, C. Sanchez, Functional Hybrid Materials, (wiley, Weinheim, 2003) p 86; Y. Wu, J. Xiang, C. Yang, W. Lu, M.C. Liber, Nature 430 (2004) 61; B. H. Kim, J.H. Jung, S.H Hong, J. Joo, A.L Epstein, K. Mizoguchi, J.W. Kim, H.J. Choi, Macromolecules 35 (2002) 1419; W.U. Huynh, J.J.Dittmer, A.P. Alivisatos, Science 295 (2002) 2425;

[2] B. Kalska-Szostko, E. Brancewicz, W. Olszewski, K. Szymański, P. Mazalski, J, Sveklo, Acta Phys. Pol. A 115 (2009) 542

[3] B. Kalska-Szostko, E. Brancewicz, W. Olszewski, K. Szymański, P. Mazalski, J, Sveklo, Solid State. Phenom. 151 (2009) 190; B. Kalska-Szostko, E. Brancewicz, E. Orzechowska, P. Mazalski, T. Wojciechowski, Mater. Sci. For. 674 (2011) 231

[4] G.D. Sułka „Wysokouporządkowane nanostruktury na anodyzowanym aluminium” Instytut Chemii Fizycznej, Uniwersytet Jagielloński

[5] P. Tomassi „Ochrona aluminium przed korozją” Instytut Mechaniki Precyzyjnej, W-wa 2006

[6] J. Choi „Fabrication of monodomain porous alumina using nanoimprint lithography and its applications" Mathematisch-Naturwissenchaftlich-Technischen Fakultät der Martin-Luther-Universität Halle-Wittenberg 2004

[7] a) B. Kalska, E. Orzechowska Mater. Chem. Phys (2011), Curr. Apel. Phys. (2011); b) H. Adelkhani, S. Nasoodi, A. H. Jafari "A study of the Morphology and Optical Properties of Electropolished Aluminum in the Vis-IR region" Int. J. Electrochem. Sci., 4 (2009) 238 - 246.

[8] A.P.Li, F. Müller, A. Birner, K.Nielch, U.Gösele "Hexagonal pore arrays with a 50-420 nm interpore distance formed by self-organization in anodic alumina", J. Appl. Phys., vol.84, p 6023, 1998 
[9] F. Li, L. Zhang, R. M. Metzger "On the growth of highly ordered pores in anodized aluminum oxide", Chem. Mater. 1998, 10, 2470-2480, A.P.Li, F. Müller, A. Birner, K.Nielch, U.Gösele "Hexagonal pore arrays with a 50-420 nm interpore distance formed by self-organization in anodic alumina" J. Appl. Phys., vol.84,(1998) p 6023 ,

[10] B. Vanderlinden, H.Terryn, J. Vereecken "Investigation of anodic aluminum-oxide layers by electrochemical impedance spectroscopy", J. Apll. Electrochem., vol. 20, p. 798,1990

[11] Ch.-G.Wu, H.L.lin, N.-L.Shan "Magnetic nanowires via template electrodeposition", J.Solid State Electrochem. 2006, 10,198-202; S.inoue, S.-Z.Chu, K. Wada, D.Li "New roots to formation of nanostructures on glass surface through anodic oxidation of sputtered aluminum" Science and Technology of Advanced Materials 4, 2003, 269-276; Y.Sui, B.Z.Cui, L.Martinez, et all.'Pore structure, barrier layer topography and matrix alumina structure of porous anodic alumina film", Thin Solid Films $406: 1-2$, 2002, 64-69; S.Lazarouk, S.Stanovski, et all."Porous alumina as low- $\varepsilon$ insulator for multilevel mettalization", Microelectronic Engineering 50 (2000) 321-327

[12] W. Szczepaniak "Metody instrumentalne w analizie chemicznej" Wydawnictwo naukowe PWN W-wa 2005, „Poradnik galwanotechnika”. Praca zbiorowa. Wyd. II poprawione, WN-Tech. W-wa 1985

[13] A. Cygański: “Metody elektroanalityczne" Wydawnictwo Naukowo-Techniczne Warszawa 1991

[14] J. Garaj: Fizyczne i fizykochemiczne metody analizay; Wydawnictwo NaukowoTechniczne Warszawa 1981

[15] Herman N.A., Kalestyoski A., Widomski L. “Fizyka dla kandydatów na wyższe uczelnie I studentów”, wyd. PWN, Warszawa 1995, P. M. S. Monk, R. J. Mortimer and D. R. Rosseinsky, Electrochromism and Electrochromic Devices, Cambridge University Press 2007

[16] R.J Gross and J.F Osterle, Membrane transport characteristics of ultrafine capillaries. J. Chem. Phys., 49 (1968), pp. 228-234

[17] S. Basu, M.M. Sharma, J. Memb.Scien. 124 (1997) 77, F. Wang, S. Arai, M. Endo, Electr. Comm. 7 (2005) 674, A. Vicenzo, P.L. Cavalloti, Electr. Acta 49 (2004) 4079, M. Motoyama, Y. Fukunaka, T. Sakka, Y.H. Ogata, Electr. Acta 53 (2007) 205

[18] M. A. V. Devanathan and B. V. Tilak, The Structure of the Electrical Double Layer at the metal-solution interface 1965

[19] C.L. Chiena, L. Sun, M. Tanase, L.A. Bauer, A. Hultgren, et al. Electrodeposited magnetic nanowires: arrays, field-induced assembly, and surface functionalization. Journal of Magnetism and Magnetic Materials 249 (2002) 146-155

[20] M.S. Dresselhausa, Y.M. Lin, O. Rabin, M.R. Black, G. Dresselhaus. Nanowires. January 2, 2003

[21] B. Kalska-Szostko, E. Orzechowska, W. Olszewski. Electrochemical deposition of Fe nanowires from nonaquaeous solution submitted for publication 
[22] A. Jagminas, R. Juškènas, I. Gailiūtė, G. Statkutė, R. Tomašiūnas “Electrochemical synthesis and optical characterization of copper selenide nanowires arrays within the alumina pores" Journal of Crystal Growth 294(2006) 343-348 


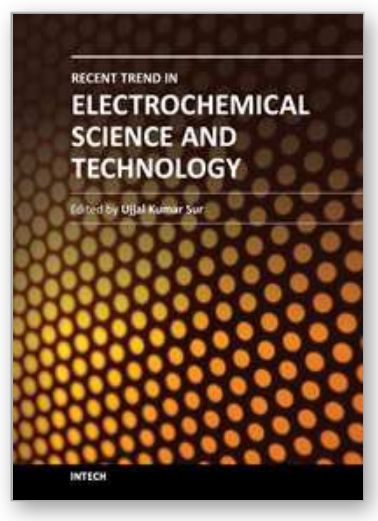

\author{
Recent Trend in Electrochemical Science and Technology \\ Edited by Dr. Ujjal Kumar Sur
}

ISBN 978-953-307-830-4

Hard cover, 306 pages

Publisher InTech

Published online 27, January, 2012

Published in print edition January, 2012

This book titled "Recent Trend in Electrochemical Science and Technology" contains a selection of chapters focused on advanced methods used in the research area of electrochemical science and technologies; descriptions of electrochemical systems; processing of novel materials and mechanisms relevant for their operation. This book provides an overview on some of the recent development in electrochemical science and technology. Particular emphasis is given both to the theoretical and the experimental aspect of modern electrochemistry. Since it was impossible to cover the rich diversity of electrochemical techniques and applications in a single issue, the focus is on the recent trends and achievements related to electrochemical science and technology.

\title{
How to reference
}

In order to correctly reference this scholarly work, feel free to copy and paste the following:

B. Kalska-Szostko (2012). Electrochemical Methods in Nanomaterials Preparation, Recent Trend in Electrochemical Science and Technology, Dr. Ujjal Kumar Sur (Ed.), ISBN: 978-953-307-830-4, InTech, Available from: http://www.intechopen.com/books/recent-trend-in-electrochemical-science-andtechnology/electrochemical-methods-in-nanomaterials-preparation

\section{INTECH}

open science | open minds

\section{InTech Europe}

University Campus STeP Ri

Slavka Krautzeka 83/A

51000 Rijeka, Croatia

Phone: +385 (51) 770447

Fax: +385 (51) 686166

www.intechopen.com

\section{InTech China}

Unit 405, Office Block, Hotel Equatorial Shanghai

No.65, Yan An Road (West), Shanghai, 200040, China

中国上海市延安西路65号上海国际贵都大饭店办公楼 405 单元

Phone: +86-21-62489820

Fax: +86-21-62489821 
(C) 2012 The Author(s). Licensee IntechOpen. This is an open access article distributed under the terms of the Creative Commons Attribution 3.0 License, which permits unrestricted use, distribution, and reproduction in any medium, provided the original work is properly cited. 